\title{
Reappraisal of waist circumference cutoff value according to general obesity
}

\author{
Kyung-Soo Kim ${ }^{1 \dagger}$, Hyun-Ju Oh${ }^{2 \dagger}$, Young Ju Choi ${ }^{3}$, Byung Wook Huh³ ${ }^{3}$ Soo-Kyung Kim ${ }^{1 *}$, Seok Won Park', \\ Eun Jig Lee ${ }^{4}$, Yong-Wook Cho ${ }^{1}$ and Kap-Bum Huh ${ }^{3}$
}

\begin{abstract}
Background: Current criterion of waist circumference (WC) for abdominal obesity is not enough to demonstrate characteristics of obese and non-obese populations defined by BMI. The aim of this study was to redefine the cutoff values of WC according to general obesity (BMl $\geq 25 \mathrm{~kg} / \mathrm{m}^{2}$ ).

Methods: The receiver operating characteristic curve analysis was performed to determine cutoff values of WC for predicting atherosclerosis according to BMI in 1,063 non-diabetic subjects. To validate this new criterion, diabetic patients ( $n=3,690$ ) were divided into three groups based on the current (WC of $90 / 80 \mathrm{~cm}$ for men/women) and new cutoff values of WC: 1) group with WC below the lowest value of two criteria; 2 ) intermediate group defined as having a WC between them; and 3) group with WC more than the highest value of them.

Results: The new cutoff values of WC for predicting atherosclerosis in non-diabetic subjects were $84 / 76 \mathrm{~cm}$ for non-obese men/women, and 93/87 cm for obese men/women, respectively. Of non-obese diabetic patients, the intermediate group (WC 84 90/76 $80 \mathrm{~cm}$ for men/women) was more insulin resistant and showed elevated odds ratio (OR) for having 2 or more metabolic risk factors compared to group with WC below 84/76 cm for men/ women [OR 2.48 (95 \% Cl 1.89-3.25) in men, 2.01 (95\% Cl 1.45-2.78) in women]. In contrast, among obese diabetic patients, insulin resistance and the likelihood of having 2 or more metabolic risk factors were not different from the intermediate group (WC $90 \sim 93 / 80 \sim 87 \mathrm{~cm}$ for men/women) and group with WC below 90/80 cm for men/ women.
\end{abstract}

Conclusions: The current universal cutoff values of WC may under- or over-estimate the metabolic risks of intermediate groups. Therefore, the WC criteria for abdominal obesity should be applied differently depending on the BMI.

Keywords: Waist circumference, Obesity, Abdominal obesity

\section{Background}

Obesity is known as a potent risk factor for metabolic disorder and cardiovascular disease [1]. The relationship between obesity and cardiovascular disease depends not only on the amount of body fat but also on its distribution $[2,3]$. Recently, increasing evidence has shown that abdominal obesity is critical risk factor for the development of insulin resistance, metabolic syndrome, type 2 diabetes, and cardiovascular disease [4-7]. Abdominal obesity is defined according to ethnically specific values of waist circumference (WC). The cutoff value for abdominal

\footnotetext{
* Correspondence: imdrksk@chollian.net

${ }^{\dagger}$ Equal contributors

${ }^{1}$ Department of Internal Medicine, CHA Bundang Medical Center, CHA

University, Seongnam, Republic of Korea

Full list of author information is available at the end of the article
}

obesity in the Korean population was defined as $\geq 90 \mathrm{~cm}$ for men and $\geq 80 \mathrm{~cm}$ for women according to AsianPacific guideline [8].

However, without consideration for general obesity, it is not appropriate that we use same WC cutoff value for abdominal obesity. For instance, individuals who have been described as "metabolically healthy obese", the obese phenotype may exist in the absence of metabolic abnormalities such as dyslipidemia, insulin resistance, hypertension and an unfavorable inflammatory profile [9-11]. Similarly not all non-obese individuals present with a healthy metabolic profile [12]. Such discrepancies between obesity and metabolic abnormalities have been explained by several factors, including fat distribution [13]. It is necessary to separately define the precise criteria for abdominal obesity by 
WC according to the presence or absence of general obesity. However, to the best of our knowledge, no previous studies have attempted to redefine the cutoff value of WC for abdominal obesity in each obese and non-obese individual. The aim of this study was to redefine the cutoff value of WC for abdominal obesity according to general obesity.

\section{Methods}

\section{Subjects}

In the present study, 1,063 non-diabetic subjects were enrolled who had undergone a medical check-up at the Korea Association of Health Promotion Center in Seoul, Korea. In addition, 3,690 consecutive patients with type 2 diabetes who visited diabetes clinic at the Huh's Diabetes Center, Seoul, Korea were also enrolled. All participants were aged 18 years or above and individuals with acute disease, known liver or kidney disease, or a history of cancer were excluded. Anthropometric assessments were performed, blood pressure was measured, and laboratory tests and carotid ultrasonography were performed in all study participants. To evaluate insulin resistance in diabetic patients, a short insulin tolerance test (SITT) was performed and assessed by the rate constant for plasma glucose disappearance (Kitt). Medical histories were collected through personal interview. All participants signed consent forms and the Institutional Review Board of Severance Hospital at Yonsei University College of Medicine approved this study.

\section{Clinical and laboratory measurements}

Height and weight were measured in all subjects while wearing light clothing and no shoes. WC was measured at the midpoint between the inferior border of the subcostal margin and iliac crest in the mid-axillary line after normal expiration with the subject standing. Blood pressure was measured using a mercury sphygmomanometer in a sitting position after the participants had remained seated for $10 \mathrm{~min}$. Venous blood samples were obtained after an overnight fast of at least $8 \mathrm{~h}$ and fasting plasma glucose, total cholesterol, triglyceride, and high-density lipoprotein (HDL)-cholesterol were measured. Hemoglobin $\mathrm{A}_{1 \mathrm{c}}\left(\mathrm{HbA}_{1 \mathrm{c}}\right)$ was analyzed using high performance liquid chromatography (Variant II, Bio-Rad, CA, U.S.A.) in subjects with type 2 diabetes.

\section{Assessment of mean carotid artery intima-media thickness (C-IMT)}

The common carotid arteries were scanned bilaterally using a high-resolution real-time B-mode ultrasonography (Toshiba SSA-270A, Japan in non-diabetic subjects; LOGIQ 7, GE, Milwaukee, WI, USA, in diabetic subjects) with a $10-\mathrm{MHz}$ linear transducer. Scanning was performed at the mid- and distal-common carotid artery by a lateral longitudinal projection. The C-IMT was measured at three points on the far wall of the midand distal-common carotid artery, $1 \mathrm{~cm}$ proximal to the dilatation of the carotid bulb, and the mean value of six measurements from the right and left common carotid arteries were used. C-IMT was defined as the distance between the lumen-intima interface and the mediaadventitia interface. A plaque was defined as a localized protrusion into the vessel lumen with thickening of the vessel wall of $>50 \%$ compared to the adjacent C-IMT.

\section{Measurement of insulin resistance}

The SITT was carried out at 8.00 a.m., after an overnight fast. With the subject at rest, $0.1 \mathrm{U}$ per $\mathrm{kg}$ of body weight of a 100 times diluted short-acting human insulin (Humulin-R, Eli Lilly, IN, U.S.A.) was administered via the vein, and a blood sample was obtained from the opposite vein at $0,3,6,9,12$, and 15 min. Plasma glucose concentrations were determined immediately after sampling using a Beckman glucose analyzer II (Beckman Ins., Fullertone, CA, USA), and then Kitt was calculated from the slope of the fall in log transformed plasma glucose between 3 and $15 \mathrm{~min}$. Immediately after the test, $100 \mathrm{~mL}$ of $20 \%$ dextrose solution was administered intravenously to avoid potential hypoglycemia.

\section{Definitions of general obesity, atherosclerosis, and metabolic risk factors}

General obesity was defined as a BMI $\geq 25 \mathrm{~kg} / \mathrm{m}^{2}$. Atherosclerosis was defined as history of coronary artery disease or cerebrovascular disease or presence of plaque or thickened C-IMT greater than 1 SD compared with age \& sex matched mean value in non-diabetic subjects [14] (Additional file 1: Table S1). We used the criteria for metabolic risk factors proposed by the modified National Cholesterol Education Program Adult Treatment Panel III definition: high serum triglyceride levels $(\geq 150 \mathrm{mg} / \mathrm{dL})$, high blood pressure (systolic, $\geq 130 \mathrm{mmHg}$; diastolic, $\geq$ $85 \mathrm{mmHg}$; or the use of antihypertensive medications), low serum HDL-cholesterol levels $(<40 \mathrm{mg} / \mathrm{dL}$ for men, $<$ $50 \mathrm{mg} / \mathrm{dL}$ for women) [15].

\section{Statistical analysis}

The receiver operating characteristic (ROC) curve analysis was performed to determine cutoff values of WC yielding the maximum sensitivity and specificity for predicting atherosclerosis in non-diabetic subjects. The new cutoff was chosen by maximizing the sums of the Youden's index where (sensitivity + specificity) -1 .

To validate these new criteria, diabetic patients were divided into three groups based on the current (WC of 90/80 cm for men/women) and new cutoff values of WC according to gender and general obesity: 1) group with WC below the lowest value of two criteria; 2) intermediate group defined as having a WC between them; and 3) 
group with WC more than the highest value of them. Data for continuous variables are presented as the mean \pm SD and categorical factors are reported as percentages. Comparisons between the groups were tested using the chi-Square test or one-way ANOVA followed by Tukey's b post-hot test, as appropriate. Odds ratios (OR) for having 2 or more metabolic risk factors in each group were determined using logistic regression analysis, and the group having WC below the lowest value of current and new criteria was used as the reference. ANCOVA was used to adjust for age, diabetes duration, current smoking, and medication usage in multivariate analysis. A $p$ value $<0.05$ was considered significant. All statistical analyses were performed using IBM SPSS Statistics (version 19.0; IBM Co., Somers, NY, USA).

\section{Results}

Table 1 shows the clinical and biochemical characteristics of the non-diabetic subjects. The mean age was 51.1 years and the mean BMI was $24.5 \mathrm{~kg} / \mathrm{m}^{2}$. Approximately $21 \%$ of the men and $25 \%$ of the women were found to have atherosclerosis.

The optimal WC measurements as obtained from ROC curves were used for predicting atherosclerosis in non-diabetic subjects were $84 \mathrm{~cm}$ in non-obese men, $76 \mathrm{~cm}$ in non-obese women, $93 \mathrm{~cm}$ in obese men, and $87 \mathrm{~cm}$ in obese women, respectively. These new cutoff values displayed the maximal Youden's index compared with current cutoff values. Sensitivity, specificity, positive and negative predictive values are also presented in Table 2.

When applying the current and new cutoff values of WC in diabetic patients, the intermediate group was defined as having WC between $84 \sim 90 \mathrm{~cm} / 76 \sim 80 \mathrm{~cm}$ for non-obese $\left(\mathrm{BMI}<25 \mathrm{~kg} / \mathrm{m}^{2}\right)$ men/women, or having WC between $90 \sim 93 \mathrm{~cm} / 80 \sim 87 \mathrm{~cm}$ for obese (BMI $\geq$ $25 \mathrm{~kg} / \mathrm{m}^{2}$ ) men/women. In non-obese diabetic patients, the intermediate group had higher blood pressure, higher triglyceride and lower HDL-cholesterol levels than the group with $\mathrm{WC}$ of $<84 / 76 \mathrm{~cm}$ for men/women. The intermediate group tended to have similar metabolic profiles as the group with WC of $\geq 90 / 80 \mathrm{~cm}$ for men/ women. C-IMT was higher in the intermediate group of non-obese diabetic women than that in the group with $\mathrm{WC}$ of $<76 \mathrm{~cm}$. Fasting glucose, $\mathrm{HbA}_{1 \mathrm{c}}$, and the frequency of atherosclerosis did not different among each group (Table 3). In contrast, among obese diabetic patients, metabolic components such as fasting glucose, blood pressure, and lipid profiles were similar in the three groups, except systolic blood pressure in obese men and $\mathrm{HbA}_{1 \mathrm{c}}$ and triglyceride in obese women. CIMT and the frequency of atherosclerosis did not differ significantly between the intermediate group and the group with WC of $<90 / 80 \mathrm{~cm}$ (Table 3 ).

Significant differences were seen in insulin resistance defined by Kitt between non-obese diabetic group with WC of $<84 / 76 \mathrm{~cm}$ for men/women and the others, but no difference was found between the intermediate group

Table 1 Clinical and biochemical characteristics of the non-diabetic subjects according to sex

\begin{tabular}{|c|c|c|c|}
\hline & Men & Women & Total \\
\hline $\mathrm{N}$ & 565 & 498 & 1063 \\
\hline Age (years) & $49.9 \pm 11.4$ & $52.5 \pm 9.9$ & $51.1 \pm 10.8$ \\
\hline Height (cm) & $168.8 \pm 5.7$ & $155.4 \pm 5.1$ & $162.5 \pm 8.6$ \\
\hline Weight (kg) & $69.4 \pm 9.1$ & $59.6 \pm 8.5$ & $64.8 \pm 10.1$ \\
\hline Body mass index $\left(\mathrm{kg} / \mathrm{m}^{2}\right)$ & $24.3 \pm 2.8$ & $24.7 \pm 3.2$ & $24.5 \pm 3.0$ \\
\hline History of coronary artery disease, n (\%) & $19(3.4)$ & $28(5.6)$ & $47(4.4)$ \\
\hline History of cerebrovascular disease, $\mathrm{n}(\%)$ & $14(2.5)$ & $14(2.8)$ & $28(2.6)$ \\
\hline Waist circumference (cm) & $86.2 \pm 7.5$ & $82.1 \pm 8.5$ & $84.3 \pm 8.2$ \\
\hline Systolic blood pressure (mm Hg) & $129.9 \pm 17.5$ & $131.0 \pm 20.0$ & $130.4 \pm 18.7$ \\
\hline Diastolic blood pressure (mm Hg) & $80.4 \pm 11.9$ & $79.9 \pm 12.7$ & $80.2 \pm 12.3$ \\
\hline Fasting glucose (mg/dL) & $96.6 \pm 14.9$ & $93.3 \pm 14.7$ & $95.0 \pm 14.9$ \\
\hline Total cholesterol (mg/dL) & $199.0 \pm 33.1$ & $206.1 \pm 37.2$ & $202.3 \pm 35.2$ \\
\hline Triglyceride (mg/dL) & $188.8 \pm 134.8$ & $148.4 \pm 146.2$ & $169.8 \pm 141.6$ \\
\hline HDL-cholesterol (mg/dL) & $44.0 \pm 9.8$ & $51.2 \pm 13.7$ & $47.3 \pm 12.3$ \\
\hline C-IMT (mm) & $0.68 \pm 0.17$ & $0.68 \pm 0.16$ & $0.68 \pm 0.16$ \\
\hline Carotid plaque, n (\%) & $28(5.0)$ & $26(5.2)$ & $54(5.1)$ \\
\hline Atherosclerosis, n (\%) & $120(21.2)$ & $126(25.3)$ & $246(23.1)$ \\
\hline
\end{tabular}

Data are expressed as the mean \pm standard deviation or number 
Table 2 Comparison of waist circumference cutoff values for abdominal obesity to predict atherosclerosis in non-diabetic subjects

\begin{tabular}{|c|c|c|c|c|c|c|c|}
\hline & & Cutoff $(\mathrm{cm})$ & Sensitivity (\%) & Specificity (\%) & PPV (\%) & NPV (\%) & Youden's index \\
\hline \multirow[t]{4}{*}{ Non-obese $\left(\mathrm{BMl}<25 \mathrm{~kg} / \mathrm{m}^{2}\right)$} & Men & 84 & 57.6 & 66.9 & 26.8 & 88.3 & 24.5 \\
\hline & & 90 & 16.9 & 95.0 & 41.7 & 84.5 & 11.9 \\
\hline & Women & 76 & 75.4 & 47.2 & 28.7 & 87.2 & 22.6 \\
\hline & & 80 & 46.2 & 68.0 & 28.8 & 81.8 & 14.2 \\
\hline \multirow[t]{4}{*}{ Obese (BMI $\geq 25$ kg/m²) } & Men & 90 & 68.9 & 37.8 & 29.2 & 76.5 & 6.7 \\
\hline & & 93 & 44.3 & 67.7 & 33.8 & 76.6 & 12.0 \\
\hline & Women & 80 & 98.4 & 8.5 & 31.7 & 92.3 & 6.9 \\
\hline & & 87 & 70.5 & 53.2 & 39.4 & 80.6 & 23.7 \\
\hline
\end{tabular}

PPV positive predictive value; NPV negative predictive value

and the group with $\mathrm{WC}$ of $\geq 90 / 80 \mathrm{~cm}$ for men/women (Fig. 1a and b). In obese diabetic patients, the intermediate group had higher Kitt values than the group with $W C$ of $\geq 93 / 87 \mathrm{~cm}$ for men/women. Kitt did not differ between the intermediate group and the group with WC of $<80 \mathrm{~cm}$ for women (Fig. 1c and d).

The ORs for having 2 or more metabolic risk factors according to WC categorized by new and current cutoff values in diabetic patients are shown in Table 4. Of nonobese diabetic patients, the intermediate group were 2.48 times (95\% CI 1.89-3.25) in men and 2.01 times (1.45-2.78) in women, more likely to have 2 or more metabolic risk factors compared to the group with WC below 84/76 cm for men/women, after adjusting for age, diabetes duration, smoking status, and medication usage. In contrast, in obese diabetic patients, ORs were not significantly different between the intermediate group and the group with WC below $90 / 80 \mathrm{~cm}$ for men/women.

\section{Discussion}

It has been well known that abdominal obesity and visceral fat, in particular, play an important role in various cardiovascular and metabolic diseases [4-7]. Because BMI does not distinguish the distribution of fat, WC, which is mainly correlated with the distribution of visceral adipose tissue, has been recommended for the specific assessment of abdominal obesity [16-18]. However, current criterion of WC for abdominal obesity is not enough to demonstrate characteristics of obese and non-obese populations defined by BMI. In the present study, we had separately redefined the cutoff value of WC in obese and non-obese population. Our findings may suggest that the current cutoff value of $\mathrm{WC}$ underestimated metabolic risks in some non-obese people and overestimated that in some obese people.

In the Asian-Pacific region, the cutoff value for abdominal obesity is defined as $\geq 90 \mathrm{~cm}$ for men and $\geq 80 \mathrm{~cm}$ for women [8]. The WC cutoffs have been based on available data linking WC with cardiovascular disease and other metabolic syndrome components in different populations [19]. The Korean Society for the Study of Obesity suggested Korean-specific WC cut points of $90 \mathrm{~cm}$ for men and $85 \mathrm{~cm}$ for women [20]. In addition, WC cutoff values for identifying the presence of insulin resistance and visceral obesity were proposed as $87 \mathrm{~cm}$ for men and $81 \mathrm{~cm}$ for women in Koreans with type 2 diabetes [21]. However, because abdominal obesity as defined by WC is not enough to capture or explain the metabolic risks for the whole population, other factors such as age and BMI should also be considered. In Japanese-American subjects, a study reported age and gender-specific cut points for abdominal obesity with the International Diabetes Federation criteria. For men, the optimal cut points for WC were $90.0 \mathrm{~cm}$ (age $<57$ years) and $87.1 \mathrm{~cm}$ (age $\geq 57$ years). For women, the optimal cut points for WC were $80.8 \mathrm{~cm}$ (age $<56$ years) and $89.0 \mathrm{~cm}$ (age $\geq 56$ years) [22]. These results indicated that WC cutoff values were different according to age. Another study on abdominal obesity found different sets of $\mathrm{WC}$ values associated with increased risk for cardiovascular disease at the designated BMI values: $90 \mathrm{~cm}$ for men and $83 \mathrm{~cm}$ for women at $25 \mathrm{~kg} / \mathrm{m}^{2}$ BMI and $100 \mathrm{~cm}$ for men and $93 \mathrm{~cm}$ for women at $30 \mathrm{~kg} / \mathrm{m}^{2}$ BMI [23]. But, to the best of our knowledge, no previous studies have explored WC cutoff values according to general obesity.

Accumulating evidence suggests that not all obese subjects are at increased cardiometabolic risk and not all nonobese are at lower risk. The term, metabolically healthy obesity, has been used to describe an obese phenotype that does not have the burden of any metabolic disorder [9-13]. Conversely, metabolically unhealthy non-obese subjects have been defined as normal BMI and having various metabolic risk factors [12, 13]. Insulin resistance, blood pressure, fasting glucose, lipid profiles, and inflammatory markers are included to define metabolic health but there is no standard definition to discriminate metabolically healthy individuals from those that are metabolically unhealthy $[10,24-26]$. In the present study, metabolic profiles such as triglyceride and HDLcholesterol concentrations and Kitt in the intermediate group (WC of $84 \sim 90 \mathrm{~cm}$ in men and $76 \sim 80 \mathrm{~cm}$ in women) are similar to those in the group with $\mathrm{WC}$ of $\geq$ 
Table 3 Clinical characteristics of diabetic patients according to sex, waist circumference (WC) and BMl

\begin{tabular}{|c|c|c|c|c|c|c|}
\hline \multirow[t]{2}{*}{ Men } & \multicolumn{3}{|c|}{ Non-obese $\left(\mathrm{BMI}<25 \mathrm{~kg} / \mathrm{m}^{2}\right)$} & \multicolumn{3}{|c|}{ Obese $\left(\mathrm{BMI} \geq 25 \mathrm{~kg} / \mathrm{m}^{2}\right)$} \\
\hline & $W C<84 \mathrm{~cm}$ & WC 84 90 cm (intermediate) & $W C \geq 90 \mathrm{~cm}$ & $W C<90 \mathrm{~cm}$ & WC 90 93 cm (intermediate) & $W C \geq 93 \mathrm{~cm}$ \\
\hline N & 839 & 347 & 56 & 398 & 166 & 309 \\
\hline Age (years) & $55.2 \pm 10.8$ & $57.5 \pm 10.1$ & $60.5 \pm 9.1^{*, * *}$ & $52.9 \pm 10.0$ & $53.6 \pm 11.1$ & $55.1 \pm 12.7$ \\
\hline Body mass index $\left(\mathrm{kg} / \mathrm{m}^{2}\right)$ & $22.1 \pm 1.8$ & $23.8 \pm 0.9^{*}$ & $24.2 \pm 0.7^{*}$ & $26.2 \pm 1.0$ & $27.0 \pm 1.2^{*}$ & $28.8 \pm 2.6^{*}, * *$ \\
\hline Waist circumference (cm) & $78.5 \pm 4.6$ & $86.9 \pm 1.7^{*}$ & $92.7 \pm 2.0^{*, * *}$ & $87.1 \pm 2.5$ & $92.0 \pm 0.8^{*}$ & $98.5 \pm 5.0^{*}, * *$ \\
\hline Systolic blood pressure $(\mathrm{mm} \mathrm{Hg})$ & $128.5 \pm 17.6$ & $133.3 \pm 16.9^{*}$ & $139.4 \pm 17.7^{*}$ & $134.3 \pm 16.6$ & $135.0 \pm 15.1$ & $138.1 \pm 15.3^{*, *}$ \\
\hline Diastolic blood pressure (mm Hg) & $83.1 \pm 11.0$ & $86.4 \pm 10.9^{*}$ & $89.7 \pm 11.9^{*},{ }^{* *}$ & $88.6 \pm 11.2$ & $89.0 \pm 10.2$ & $89.9 \pm 11.6$ \\
\hline Fasting glucose (mg/dL) & $163.2 \pm 67.3$ & $158.7 \pm 53.2$ & $145.8 \pm 47.0$ & $151.8 \pm 49.9$ & $149.2 \pm 47.7$ & $152.5 \pm 53.3$ \\
\hline $\mathrm{HbA}_{1 \mathrm{C}}(\%)$ & $8.5 \pm 2.3$ & $8.3 \pm 1.8$ & $7.9 \pm 1.1$ & $8.0 \pm 1.7$ & $7.9 \pm 1.4$ & $8.2 \pm 1.9$ \\
\hline $\mathrm{HbA}_{1 \mathrm{C}}(\mathrm{mmol} / \mathrm{mol})$ & $69 \pm 25$ & $67 \pm 20$ & $63 \pm 12$ & $64 \pm 19$ & $63 \pm 15$ & $66 \pm 21$ \\
\hline Total cholesterol (mg/dL) & $186.5 \pm 39.7$ & $189.2 \pm 34.8$ & $193.5 \pm 44.7$ & $185.9 \pm 37.9$ & $185.8 \pm 35.8$ & $190.2 \pm 36.5$ \\
\hline Triglyceride (mg/dL) & $117.8 \pm 71.8$ & $153.8 \pm 83.2^{*}$ & $164.2 \pm 92.5^{*}$ & $154.7 \pm 84.6$ & $151.9 \pm 69.4$ & $162.3 \pm 71.1$ \\
\hline HDL-cholesterol (mg/dL) & $51.8 \pm 14.1$ & $46.4 \pm 12.1^{*}$ & $45.4 \pm 13.2^{*}$ & $45.5 \pm 10.7$ & $46.0 \pm 10.5$ & $44.8 \pm 10.8$ \\
\hline C-IMT (mm) & $0.85 \pm 0.19$ & $0.88 \pm 0.20$ & $0.91 \pm 0.20^{*}$ & $0.84 \pm 0.18$ & $0.86 \pm 0.19$ & $0.89 \pm 0.19^{*}$ \\
\hline Diabetes duration (year) & $8.8 \pm 8.1$ & $8.6 \pm 7.7$ & $8.4 \pm 7.2$ & $6.8 \pm 6.4$ & $6.8 \pm 7.0$ & $6.5 \pm 7.2$ \\
\hline Atherosclerosis (\%) & $362(43.1)$ & $156(45.0)$ & $25(44.6)$ & $175(44.0)$ & $81(48.8)$ & $156(50.5)$ \\
\hline Anti-hypertensive medication (\%) & $179(21.3)$ & $94(27.1)$ & $22(39.3)^{* * * *}$ & $110(27.6)$ & $61(36.7)$ & $120(38.8)^{* * *}$ \\
\hline Statin (\%) & $59(7.0)$ & $36(10.4)$ & $6(10.7)$ & $41(10.3)$ & $23(13.9)$ & $45(14.6)$ \\
\hline \multirow[t]{2}{*}{ Women } & \multicolumn{3}{|c|}{ Non-obese $\left(\mathrm{BMI}<25 \mathrm{~kg} / \mathrm{m}^{2}\right)$} & \multicolumn{3}{|c|}{ Obese $\left(\mathrm{BMI} \geq 25 \mathrm{~kg} / \mathrm{m}^{2}\right)$} \\
\hline & $W C<76 \mathrm{~cm}$ & WC 76 80 cm (intermediate) & $W C \geq 80 \mathrm{~cm}$ & $W C<80 \mathrm{~cm}$ & WC 80 87 cm (intermediate) & $W C \geq 87 \mathrm{~cm}$ \\
\hline N & 506 & 242 & 218 & 69 & 267 & 273 \\
\hline Age (years) & $57.0 \pm 9.5$ & $59.3 \pm 9.5^{*}$ & $60.2 \pm 7.8^{*}$ & $57.9 \pm 10.8$ & $58.9 \pm 9.5$ & $59.8 \pm 9.0$ \\
\hline Body mass index $\left(\mathrm{kg} / \mathrm{m}^{2}\right)$ & $21.3 \pm 1.9$ & $23.1 \pm 1.1^{*}$ & $23.8 \pm 0.9^{*, * *}$ & $26.1 \pm 1.1$ & $27.0 \pm 1.3^{*}$ & $29.2 \pm 2.8^{*, * *}$ \\
\hline Waist circumference (cm) & $71.4 \pm 4.3$ & $78.4 \pm 1.1^{*}$ & $83.9 \pm 2.6^{*}, * *$ & $78.6 \pm 1.7$ & $84.4 \pm 1.9^{*}$ & $92.7 \pm 4.6^{*}, * *$ \\
\hline Systolic blood pressure (mm Hg) & $131.6 \pm 19.3$ & $137.0 \pm 17.1^{*}$ & $138.6 \pm 19.9^{*}$ & $138.7 \pm 15.6$ & $139.3 \pm 17.8$ & $142.8 \pm 18.9$ \\
\hline Diastolic blood pressure (mm Hg) & $81.7 \pm 11.4$ & $84.3 \pm 10.0^{*}$ & $84.8 \pm 11.3^{*}$ & $85.5 \pm 9.3$ & $85.1 \pm 10.8$ & $87.9 \pm 11.9$ \\
\hline Fasting glucose (mg/dL) & $154.6 \pm 64.0$ & $157.1 \pm 58.7$ & $153.5 \pm 53.7$ & $143.1 \pm 52.8$ & $147.3 \pm 51.1$ & $153.0 \pm 54.0$ \\
\hline $\mathrm{HbA}_{1 \mathrm{C}}(\%)$ & $8.1 \pm 2.1$ & $8.3 \pm 1.7$ & $8.4 \pm 1.7$ & $7.8 \pm 1.8$ & $8.0 \pm 1.7$ & $8.3 \pm 1.6^{*}$ \\
\hline $\mathrm{HbA}_{1 \mathrm{c}}(\mathrm{mmol} / \mathrm{mol})$ & $66 \pm 23$ & $67 \pm 19$ & $68 \pm 19$ & $62 \pm 20$ & $64 \pm 19$ & $67 \pm 18^{*}$ \\
\hline Total cholesterol (mg/dL) & $192.4 \pm 39.4$ & $200.4 \pm 41.4^{*}$ & $202.4 \pm 37.1^{*}$ & $197.0 \pm 34.5$ & $202.4 \pm 39.4$ & $203.4 \pm 38.5$ \\
\hline Triglyceride (mg/dL) & $111.0 \pm 63.4$ & $146.7 \pm 79.3^{*}$ & $153.0 \pm 78.4^{*}$ & $129.2 \pm 54.5$ & $147.3 \pm 73.6$ & $161.4 \pm 73.3^{*}$ \\
\hline
\end{tabular}


Table 3 Clinical characteristics of diabetic patients according to sex, waist circumference (WC) and BMI (Continued)

\begin{tabular}{|c|c|c|c|c|c|c|}
\hline$\overline{\mathrm{HDL} \text {-cholesterol (mg/dL) }}$ & $58.0 \pm 14.7$ & $52.7 \pm 13.0^{*}$ & $51.8 \pm 12.8^{*}$ & $50.3 \pm 11.9$ & $51.7 \pm 11.5$ & $48.9 \pm 12.7$ \\
\hline C-IMT (mm) & $0.80 \pm 0.18$ & $0.83 \pm 0.16^{*}$ & $0.85 \pm 0.17^{*}$ & $0.82 \pm 0.17$ & $0.85 \pm 0.19$ & $0.86 \pm 0.17$ \\
\hline Diabetes duration (year) & $8.5 \pm 7.2$ & $8.8 \pm 7.1$ & $9.4 \pm 7.2$ & $6.3 \pm 6.6$ & $7.3 \pm 6.8$ & $7.8 \pm 6.9$ \\
\hline Atherosclerosis (\%) & $214(42.3)$ & $116(47.9)$ & $107(49.1)$ & $34(49.3)$ & $132(49.4)$ & $144(52.7)$ \\
\hline Anti-hypertensive medication (\%) & $130(25.7)$ & $94(38.8)$ & $79(36.2)^{* * *}$ & $23(33.3)$ & $100(37.5)$ & $126(46.2)^{* * *}$ \\
\hline Statin (\%) & 67 (13.2) & 40 (16.5) & 36 (16.5) & $9(13.0)$ & 35 (13.1) & $42(15.4)$ \\
\hline
\end{tabular}

Data are expressed as the mean \pm standard deviation or number

$H D L$ high-density lipoprotein; C-IMT mean carotid artery intima-media thickness

${ }^{*} P<0.05$ vs. Group with WC of $<84 / 76 \mathrm{~cm}$ for non-obese men/women or group with $W C$ of $<90 / 80 \mathrm{~cm}$ for obese men/women

${ }^{* *} P<0.05$ vs. Intermediate group

$P<0.05$ 


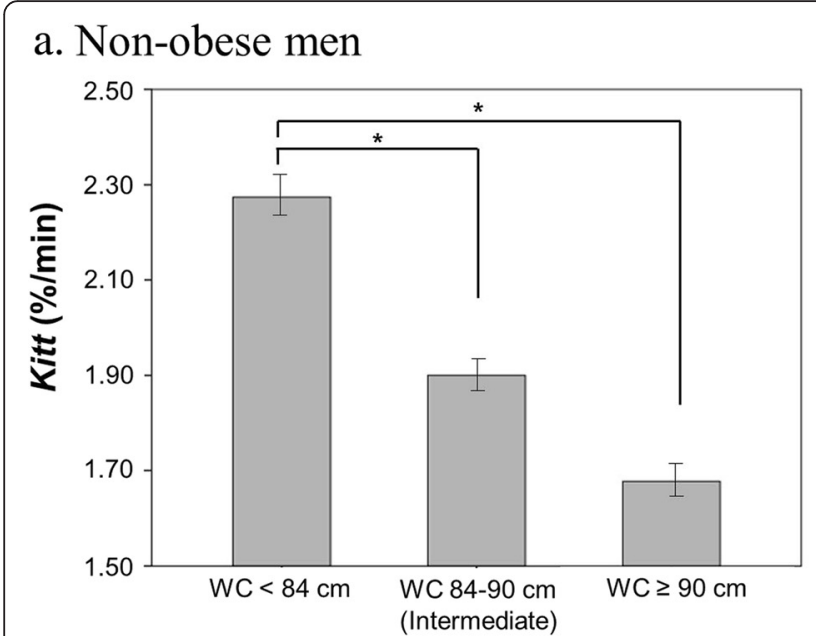

\section{c. Obese men}

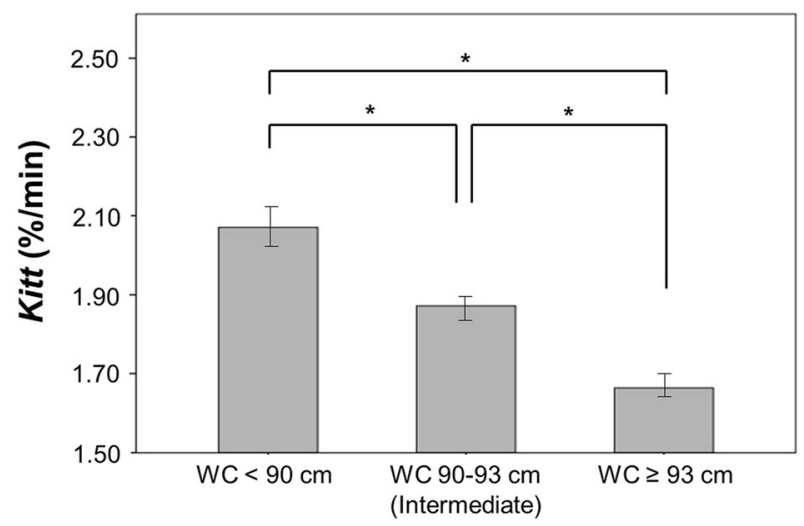

b. Non-obese women

d. Obese women
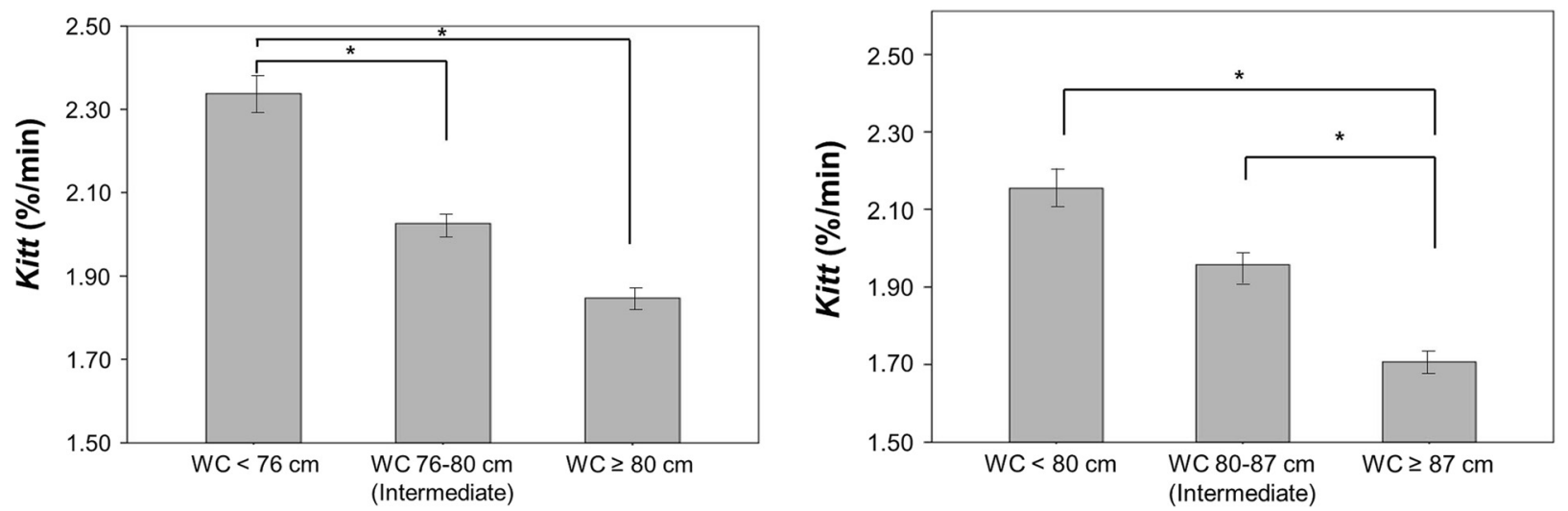

Fig. 1 Differences in a Kitt (\%/min) according to current and new cutoff values of waist circumference (WC) in diabetic patients. a in non-obese men; b in non-obese women; $\mathbf{c}$ in obese men; $\mathbf{d}$ in obese women. In non-obese patients, intermediate group represent lower Kitt value compared to group with WC of $<84 / 76 \mathrm{~cm}$ in men/women. In obese patients, intermediate group represent higher Kitt value than group with WC of $\geq 93 / 87 \mathrm{~cm}$ in men/women. ${ }^{*}, p<0.05$

90/80 $\mathrm{cm}$ for men/women among non-obese diabetic patients. This intermediate group may represent the characteristics of the metabolically unhealthy nonobese population $[13,27]$. On the other hand, in the obese diabetic patients, the intermediate group (WC of
$90 \sim 93 \mathrm{~cm}$ in men and $80 \sim 87 \mathrm{~cm}$ in women) had similar metabolic profiles to the group with WC of $<90 / 80 \mathrm{~cm}$ for men/women. This finding is compatible with previously published data on metabolically healthy obese participants [12, 28]. Therefore, in order to

Table 4 Odds ratios for predicting 2 or more metabolic risk factors in diabetic patients

\begin{tabular}{|c|c|c|c|c|c|c|}
\hline \multirow[t]{2}{*}{ Men } & \multicolumn{3}{|c|}{ Non-obese $\left(\mathrm{BMl}<25 \mathrm{~kg} / \mathrm{m}^{2}\right)$} & \multicolumn{3}{|c|}{ Obese $\left(\mathrm{BMI} \geq 25 \mathrm{~kg} / \mathrm{m}^{2}\right)$} \\
\hline & $W C<84 \mathrm{~cm}$ & WC 84 90 cm (intermediate) & $W C \geq 90 \mathrm{~cm}$ & $W C<90 \mathrm{~cm}$ & WC 90 93 cm (intermediate) & $W C \geq 93 \mathrm{~cm}$ \\
\hline Unadjusted OR & 1 & $2.52(1.94-3.29)$ & $4.65(2.67-8.10)$ & 1 & $1.00(0.70-1.44)$ & $1.44(1.07-1.94)$ \\
\hline Adjusted $O R^{a}$ & 1 & $2.48(1.89-3.25)$ & $4.39(2.48-7.75)$ & 1 & $0.96(0.66-1.39)$ & $1.47(1.08-2.00)$ \\
\hline \multirow[t]{2}{*}{ Women } & \multicolumn{3}{|c|}{ Non-obese $\left(\mathrm{BMI}<25 \mathrm{~kg} / \mathrm{m}^{2}\right)$} & \multicolumn{3}{|c|}{ Obese $\left(\mathrm{BMl} \geq 25 \mathrm{~kg} / \mathrm{m}^{2}\right)$} \\
\hline & $W C<76 \mathrm{~cm}$ & WC 76 80 cm (intermediate) & $W C \geq 80 \mathrm{~cm}$ & $W C<80 \mathrm{~cm}$ & WC $80 \sim 87 \mathrm{~cm}$ (intermediate) & $W C \geq 87 \mathrm{~cm}$ \\
\hline Unadjusted OR & 1 & $2.29(1.67-3.14)$ & $2.91(2.09-4.03)$ & 1 & $0.90(0.53-1.53)$ & $1.72(1.00-2.94$ \\
\hline Adjusted $O R^{a}$ & 1 & $2.01(1.45-2.78)$ & $2.51(1.78-3.54)$ & 1 & $0.91(0.53-1.57)$ & $1.75(1.00-3.05$ \\
\hline
\end{tabular}

${ }^{\mathrm{a}}$ Adjusted for age, diabetes duration, smoking status, medication usage (insulin, oral anti-diabetic drugs, anti-hypertensive medication, statin) 
distinguish these groups more accurately, it is necessary to redefine WC cutoff values for abdominal obesity based on their general obesity (as defined from BMI).

Similar to the intermediate group in non-obese diabetic patients, metabolically unhealthy non-obese subjects were more commonly found in the Asian population than in Western population [29]. The studies have shown that Asians have a higher level of visceral fat within the same BMI values compared to Caucasians, so the increased risk for metabolic syndrome and cardiovascular disease is present [30, 31]. In a Finnish type 2 diabetes survey, metabolically unhealthy non-obese individuals had higher 2-h postload glucose levels $(p=0.003)$, higher non-alcoholic fatty liver disease scores $(p<0.001)$, and higher cardiovascular disease risk scores (Framingham, $p<0.001$; SCORE, $p=0.002$ ) than metabolically healthy obese individuals [32]. Therefore, it might be necessary to lower WC cutoff values in individuals with normal BMI in order to appropriately manage individuals categorized into intermediate group.

Although there was no universally accepted definition of metabolically healthy obese, many studies have found that individuals with the metabolically healthy obese phenotype are not at increased risk for diabetes, cardiovascular disease, and all-cause mortality [11, 12, 33]. Conversely, metabolically healthy obesity was found to be associated with cardiovascular and all-cause mortality in some studies $[25,34,35]$. Until now, many clinicians have the perception that metabolically healthy obesity is an early stage of the metabolic risk groups. The intermediate group in obese diabetic patients might have been categorized by metabolically healthy obese in aforementioned studies. Therefore close attention should be paid to these patients and redefinition of the WC cutoff values to higher measurements than the current cutoff values to help demonstrate absolutely higher metabolic risk in the obese population should be considered.

One of the strengths in the present study was that we used atherosclerosis instead of metabolic syndrome components to define WC cutoff value for abdominal obesity. Although many studies has used metabolic syndrome components (except WC criteria) to define WC cutoff value, we chose atherosclerosis defined by C-IMT or history of coronary artery disease or cerebrovascular disease because it is a more accurate and precise marker for cardiovascular diseases. In addition, when we verified new WC cutoff values in diabetic patients, we compared insulin resistance calculated by SITT among three groups. SITT is a more accurate method for the evaluation of in vivo insulin sensitivity compared to the homeostasis model assessment of insulin resistance in humans. On the other hand, because this cross-sectional study included only the Korean population, the results cannot be applied directly to other ethnic populations. Our results might be different in other ethnic populations because the Korean population is not obese than Western population. Ultrasonography is highly operator-dependent. In the present study, however, two other sonographers performed the carotid doppler separately in the non-diabetic and the diabetic population, and the intra-observer variability was not checked. The present study investigated differences in insulin resistance and the likelihood of having poor metabolic profiles among groups, but not differences in specific atherosclerotic markers. Moreover, cardiovascular event and all-cause mortality was not fully assessed. Future prospective studies on the risk of suggested WC cutoff values and the incidence of cardiovascular morbidity and mortality are needed.

\section{Conclusions}

In conclusion, the criteria for abdominal obesity defined by current cutoff values of WC may underestimate the metabolic risks in some non-obese people and overestimate that in some obese people. The optimal cutoff of WC may be $84 / 76 \mathrm{~cm}$ in non-obese men/women and 93/87 cm in obese men/women, respectively. The application of these new cutoff values of WC according to BMI may be useful to identify the subjects with poor metabolic profile disproportionate to their underlying BMI and to prevent misclassification some metabolically healthy obese subjects were mistakenly classified as being at high risk. Therefore, we propose that the criteria of WC for abdominal obesity should be applied differently depending on the BMI.

\section{Additional file}

Additional file 1: Table S1. Mean carotid artery intima-media thickness (C-IMT) according to age in non-diabetic subjects in Korea. (DOCX 26 kb)

\section{Abbreviations}

C-IMT: carotid artery intima-media thickness; $\mathrm{HbA}_{1}$ : hemoglobin $\mathrm{A}_{1 \mathrm{c}}$; HDL: high-density lipoprotein; OR: odds ratios; ROC: receiver operating characteristic; SITT: short insulin tolerance test; WC: waist circumference.

\section{Competing interests}

The authors declare that they have no competing interests.

\section{Authors' contributions}

Author contributions include the following: K-SK and $\mathrm{H}-\mathrm{JO}$ researched data, contributed to discussion, wrote the manuscript, and reviewed and edited the manuscript. YJC and BWH researched data and contributed to discussion. S-KK researched data, contributed to discussion, and reviewed the manuscript. SWP, EJL, Y-WC, K-BH contributed to discussion and reviewed the manuscript. All authors approved the final version. S-KK is the guarantor of this work and, as such, had full access to all the data in the study and takes responsibility for the integrity of the data and the accuracy of the data analysis.

\section{Acknowledgements \\ None.}

\section{Author details}

${ }^{1}$ Department of Internal Medicine, CHA Bundang Medical Center, CHA University, Seongnam, Republic of Korea. ${ }^{2}$ Department of Internal Medicine, Bundang Jesaeng General Hospital, Seongnam, Republic of Korea. ${ }^{3}$ Huh's 
Diabetes Center and the 21th Century Diabetes and Vascular Research Institute, Seoul, Republic of Korea. ${ }^{4}$ Department of Internal Medicine, Yonsei University College of Medicine, Seoul, Republic of Korea.

Received: 12 January 2016 Accepted: 29 March 2016

Published online: 05 April 2016

\section{References}

1. Kim MK, Lee WY, Kang JH, Kang JH, Kim BT, Kim SM, Committee of Clinica Practice Guidelines. Korean Society for the Study of Obesity. 2014 clinical practice guidelines for overweight and obesity in Korea. Endocrinol Metab (Seoul). 2014;29:405-09.

2. Harman-Boehm I, Blüher M, Redel H, Sion-Vardy N, Ovadia S, Avinoach E, et al. Macrophage infiltration into omental versus subcutaneous fat across different populations: effect of regional adiposity and the comorbidities of obesity. J Clin Endocrinol Metab. 2007;92:2240-47.

3. Yu RH, Ho SC, Ho SS, Woo JL, Ahuja AT. Association of general and abdominal obesities and metabolic syndrome with subclinical atherosclerosis in asymptomatic Chinese postmenopausal women. Menopause. 2008:15:185-92.

4. Recio-Rodriguez Jl, Gomez-Marcos MA, Patino-Alonso MC, Agudo-Conde C, Rodriguez-Sanchez E, Garcia-Ortiz L, Vasorisk group. Abdominal obesity vs general obesity for identifying arterial stiffness, subclinical atherosclerosis and wave reflection in healthy, diabetics and hypertensive. BMC Cardiovasc Disord. 2012;12:3.

5. Wang $Y$, Ma X, Zhou M, Zong W, Zhang L, Hao $Y$, et al. Contribution of visceral fat accumulation to carotid intima-media thickness in a Chinese population. Int J Obes (Lond). 2012;36:1203-08.

6. Palaniappan L, Carnethon MR, Wang Y, Hanley AJ, Fortmann SP, Haffner SM, et al. Insulin Resistance Atherosclerosis Study. Predictors of the incident metabolic syndrome in adults: the Insulin Resistance Atherosclerosis Study. Diabetes Care. 2004;27:788-93.

7. Lakka HM, Lakka TA, Tuomilehto J, Salonen JT. Abdominal obesity is associated with increased risk of acute coronary events in men. Eur Heart J. 2002:23:706-13.

8. Force IOT. Asia-Pacific perspective: redefining obesity and its treatment. Sydney, Australia: Western Pacific Region; 2000

9. Stefan N, Kantartzis K, Machann J, Schick F, Thamer C, Rittig K, et al. Identification and characterization of metabolically benign obesity in humans. Arch Intern Med. 2008;168:1609-16.

10. Wildman RP, Muntner P, Reynolds K, McGinn AP, Rajpathak S, Wylie-Rosett J, et al. The obese without cardiometabolic risk factor clustering and the normal weight with cardiometabolic risk factor clustering: prevalence and correlates of 2 phenotypes among the US population (NHANES 1999-2004). Arch Intern Med. 2008;168:1617-24.

11. Hamer M, Stamatakis E. Metabolically healthy obesity and risk of all-cause and cardiovascular disease mortality. J Clin Endocrinol Metab. 2012;97: 2482-88.

12. Phillips CM. Metabolically healthy obesity: definitions, determinants and clinical implications. Rev Endocr Metab Disord. 2013;14:219-27.

13. Denis GV, Obin MS. 'Metabolically healthy obesity': origins and implications. Mol Aspects Med. 2013;34:59-70.

14. Cho YL, Kim DJ, Kim HD, Choi SH, Kim SK, Kim HJ, et al. Reference values of carotid artery intima-media thickness and association with atherosclerotic risk factors in healthy subjects in Korea. Korean J Med. 2003;64:275-83.

15. Alberti KG, Zimmet P, Shaw J, IDF Epidemiology Task Force Consensus Group. The metabolic syndrome-a new worldwide definition. Lancet. 2005;366:1059-62

16. Coutinho T, Goel K, Corrêa De Sá D, Kragelund C, Kanaya AM, Zeller M, et al. Central obesity and survival in subjects with coronary artery disease: a systematic review of the literature and collaborative analysis with individual subject data. J Am Coll Cardiol. 2011;57:1877-86.

17. Czernichow S, Kengne AP, Stamatakis E, Hamer M, Batty GD. Body mass index, waist circumference and waist-hip ratio: which is the better discriminator of cardiovascular disease mortality risk?: evidence from an individual-participant meta-analysis of 82864 participants from nine cohort studies. Obes Rev. 2011;12:680-87.

18. Park SH, Choi SJ, Lee KS, Park HY. Waist circumference and waist-to-height ratio as predictors of cardiovascular disease risk in Korean adults. Circ J. 2009;73:1643-50.
19. Lim S, Kim JH, Yoon JW, Kang SM, Choi SH, Park YJ, et al. Optimal cut points of waist circumference (WC) and visceral fat area (VFA) predicting for metabolic syndrome (MetS) in elderly population in the Korean Longitudinal Study on Health and Aging (KLOSHA). Arch Gerontol Geriatr. 2012:54:e29-34.

20. Lee SY, Park HS, Kim DJ, Han JH, Kim SM, Cho GJ, et al. Appropriate waist circumference cutoff points for central obesity in Korean adults. Diabetes Res Clin Pract. 2007;75:72-80.

21. Lim JS, Choi YJ, Kim SK, Huh BW, Lee EJ, Huh KB. Optimal Waist Circumference Cutoff Value Based on Insulin Resistance and Visceral Obesity in Koreans with Type 2 Diabetes. Diabetes Metab J. 2015:39:253-63.

22. Hayashi T, Boyko EJ, McNeely MJ, Leonetti DL, Kahn SE, Fujimoto WY. Minimum waist and visceral fat values for identifying Japanese Americans at risk for the metabolic syndrome. Diabetes Care. 2007;30:120-27.

23. Zhu S, Wang Z, Heshka S, Heo M, Faith MS, Heymsfield SB. Waist circumference and obesity-associated risk factors among whites in the third National Health and Nutrition Examination Survey: clinical action thresholds. Am J Clin Nutr. 2002;76:743-49.

24. Aguilar-Salinas CA, García EG, Robles L, Riaño D, Ruiz-Gomez DG, García-Ulloa AC, et al. High adiponectin concentrations are associated with the metabolically healthy obese phenotype. J Clin Endocrinol Metab. 2008;93:4075-79.

25. Meigs JB, Wilson PW, Fox CS, Vasan RS, Nathan DM, Sullivan LM, et al. Body mass index, metabolic syndrome, and risk of type 2 diabetes or cardiovascular disease. J Clin Endocrinol Metab. 2006:91:2906-12.

26. Karelis AD, Brochu M, Rabasa-Lhoret R. Can we identify metabolically healthy but obese individuals (MHO)? Diabetes Metab. 2004;30:569-72.

27. Ruderman N, Chisholm D, Pi-Sunyer X, Schneider S. The metabolically obese, normal-weight individual revisited. Diabetes. 1998:47:699-713.

28. Van der DL A, Nooyens AC, Van Duijnhoven FJ, Verschuren MM, Boer JM. All-cause mortality risk of metabolically healthy abdominal obese individuals: the EPIC-MORGEN study. Obesity (Silver Spring). 2014;22:557-64.

29. Expert WHO. Consultation. Appropriate body-mass index for Asian populations and its implications for policy and intervention strategies. Lancet. 2004;363:157-63.

30. World Health Organization. Obesity: preventing and managing the global epidemic. Report of a WHO consultation (WHO Technical Report Series 894). Geneva, Switzerland: World Health Organization; 2000.

31. Banerji MA, Faridi N, Atluri R, Chaiken RL, Lebovitz HE. Body composition, visceral fat, leptin, and insulin resistance in Asian Indian men. J Clin Endocrinol Metab. 1999;84:137-44.

32. Pajunen $\mathrm{P}$, Kotronen $\mathrm{A}$, Korpi-Hyövälti E, Keinänen-Kiukaanniemi S, Oksa H, Niskanen L, et al. Metabolically healthy and unhealthy obesity phenotypes in the general population: the FIN-D2D Survey. BMC Public Health. 2011;11:754.

33. Durward CM, Hartman TJ, Nickols-Richardson SM. All-cause mortality risk of metabolically healthy obese individuals in NHANES III. J Obes. 2012;2012: 460321.

34. Hinnouho GM, Czernichow S, Dugravot A, Batty GD, Kivimaki M, Singh-Manoux A. Metabolically healthy obesity and risk of mortality: does the definition of metabolic health matter? Diabetes Care. 2013;36:2294-300.

35. Kuk JL, Ardern Cl. Are metabolically normal but obese individuals at lower risk for all-cause mortality? Diabetes Care. 2009:32:2297-99.

\section{Submit your next manuscript to BioMed Central and we will help you at every step:}

- We accept pre-submission inquiries

- Our selector tool helps you to find the most relevant journal

- We provide round the clock customer support

- Convenient online submission

- Thorough peer review

- Inclusion in PubMed and all major indexing services

- Maximum visibility for your research

Submit your manuscript at www.biomedcentral.com/submit 